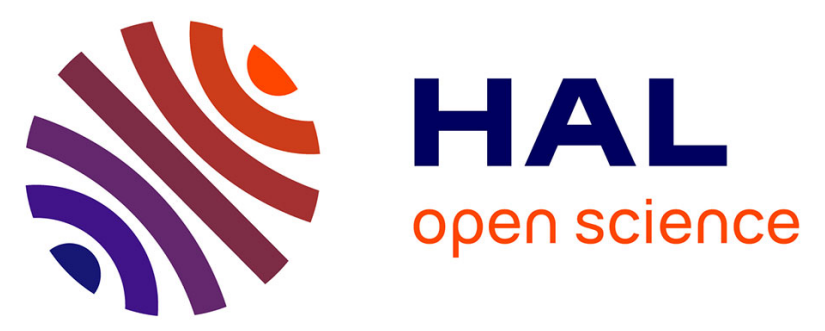

\title{
Reconstruction of uranium and plutonium isotopic signatures in sediment accumulated in the Mano Dam reservoir, Japan, before and after the Fukushima nuclear accident
}

Hugo Jaegler, Fabien Pointurier, Silvia Diez-Fernández, Alkiviadis Gourgiotis, Hélène Isnard, Seiji Hayashi, Hideki Tsuji, Yuichi Onda, Amelie Hubert, J. Patrick Laceby, et al.

\section{- To cite this version:}

Hugo Jaegler, Fabien Pointurier, Silvia Diez-Fernández, Alkiviadis Gourgiotis, Hélène Isnard, et al.. Reconstruction of uranium and plutonium isotopic signatures in sediment accumulated in the Mano Dam reservoir, Japan, before and after the Fukushima nuclear accident. Chemosphere, 2019, 225, pp.849-858. 10.1016/j.chemosphere.2019.03.064 . hal-02336278

\section{HAL Id: hal-02336278 \\ https://hal.science/hal-02336278}

Submitted on 28 Oct 2019

HAL is a multi-disciplinary open access archive for the deposit and dissemination of scientific research documents, whether they are published or not. The documents may come from teaching and research institutions in France or abroad, or from public or private research centers.
L'archive ouverte pluridisciplinaire HAL, est destinée au dépôt et à la diffusion de documents scientifiques de niveau recherche, publiés ou non, émanant des établissements d'enseignement et de recherche français ou étrangers, des laboratoires publics ou privés.

\section{(c)(1)}

Distributed under a Creative Commons Attribution| 4.0 International License 
1 Reconstruction of uranium and plutonium isotopic signatures in 2 sediment accumulated in the Mano Dam reservoir, Japan, before 3 and after the Fukushima accident

$5 \quad$ Hugo Jaegler ${ }^{1}$, Fabien Pointurier ${ }^{2}$, Silvia Diez-Fernández ${ }^{3}$, Alkiviadis Gourgiotis ${ }^{4}$, Hélène Isnard ${ }^{3}$, Seiji 6 Hayashi $^{5}$, Hideki Tsuji ${ }^{5}$, Yuichi Onda $^{6}$, Amélie Hubert $^{2}$, J. Patrick Laceby ${ }^{1,7}$ \& Olivier Evrard ${ }^{1} *$

7

8

9

\section{Affiliations:}

${ }^{1}$ Laboratoire des Sciences du Climat et de l'Environnement, LSCE/IPSL, UMR 8212 (CEA-CNRS-UVSQ), Université Paris-Saclay, F-91198 Gif-sur-Yvette Cedex, France

${ }^{2}$ CEA, DAM, DIF, F-91297 Arpajon, France

${ }^{3}$ Den - Service d'Etudes Analytiques et de Réactivité des Surfaces (SEARS), CEA, Université ParisSaclay, F-91191, Gif sur Yvette, France

${ }^{4}$ Institut de Radioprotection et de Sûreté Nucléaire - PSE/ENV - SEDRE/LELI BP 17, Fontenay-auxRoses, 92262, France

${ }^{5}$ National Institute for Environmental Science, Fukushima Branch, 10-2 Fukasaku, Miharu, Tamura, Fukushima, 963-7700 Japan

${ }^{6}$ Center for Research in Isotopes and Environmental Dynamics (CRIED), University of Tsukuba, Tsukuba, Japan

${ }^{7}$ Environmental Monitoring and Science Division, Alberta Environment and Parks, 3115 - 12 Street NE Calgary, Alberta, Canada

(*) Corresponding author (email address: olivier.evrard@|sce.ipsl.fr). 
The Fukushima Dai-ichi Nuclear Power Plant (FDNPP) accident in Japan resulted in a major release of radionuclides into the environment. Compared to others elements, few studies have investigated the emission of actinides. Accordingly, this research investigates the Pu composition in soil samples collected in nearby paddy fields before and after the accident. Furthermore, the vertical distributions of $\mathrm{Pu}$ and $\mathrm{U}$ isotopic signatures, along with ${ }^{137} \mathrm{Cs}$ activities, were measured in a sediment core collected in 2015 in the Mano Dam reservoir, in the Fukushima Prefecture. These signatures were used to quantify changes in the relative contributions of the major actinide sources (global fallout or FDNPP derived fallout) in sediment deposited in the reservoir. The distinct peak observed for all Pu isotope ratios $\left({ }^{240} \mathrm{Pu} /{ }^{239} \mathrm{Pu},{ }^{241} \mathrm{Pu} /{ }^{239} \mathrm{Pu}\right.$ and $\left.{ }^{242} \mathrm{Pu} /{ }^{239} \mathrm{Pu}\right)$ and for ${ }^{137} \mathrm{Cs}$ concentrations in the sediment core was attributed to the Fukushima fallout, and coincided with the maximum atomic contribution of only $4.8 \pm 1.0 \%$ of Pu from the FDNPP. Furthermore, ${ }^{236} \mathrm{U} /{ }^{238} \mathrm{U}$ ratios measured in the sediment core remained close to the global fallout signature indicating there was likely no $U$ from the FDNPP accident in the sediment core. More research is required on the environmental dynamics of trace actinides in landscapes closer to the FDNPP where greater abundances of FDNPP-derived Pu and U would be anticipated. 


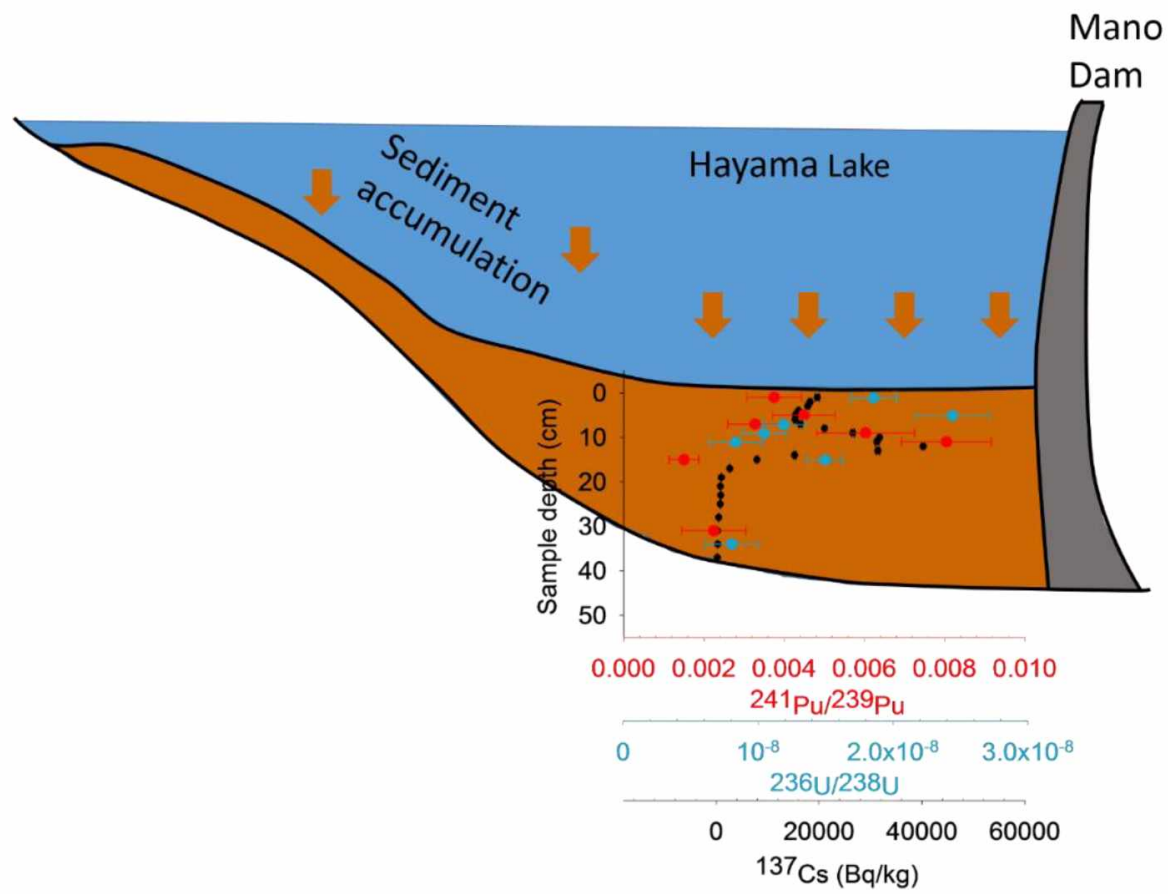

Introduction

The 2011 Fukushima Dai-ichi Nuclear Power Plant (FDNPP) accident released significant volumes of radionuclides into the environment. In particular, various venting operations and explosions occurred at the FDNPP and triggered the release of volatile fission products $\left({ }^{131} \mathrm{I},{ }^{132} \mathrm{Te},{ }^{134} \mathrm{Cs}\right.$ and $\left.{ }^{137} \mathrm{Cs}\right)($ Schneider et al., 2017). Accordingly, numerous studies were conducted to investigate the distribution and the fate of the gamma-emitting isotopes, including radiocesium, after the accident(Buesseler et al., 2016; Cao et al., 2016; Tanaka et al., 2015; Yamamoto et al., 2012; Zheng et al., 2014). Erosion and remobilisation of particle-bound radiocesium contamination was investigated through field monitoring(Evrard et al., 2016; Yamashiki et al., 2014) and model simulations(Kitamura et al., 2016; Kitamura et al., 2014). These studies reported a rapid export of the particle-bound radioactive contamination by the coastal rivers to the Pacific Ocean, with the preferential remobilisation of fine sediment particles enriched in radiocesium. This process was shown to be 
exacerbated during heavy typhoons, because of the strong hillslope-to-river sediment connectivity observed, particularly with paddy fields that were found to be one of the main sources of radiocesium shortly after the accident(Chartin et al., 2017; Laceby et al., 2016; Lepage et al., 2016). Importantly, dams and reservoirs were demonstrated to store significant quantities of contaminated sediment in the region and their management represents a significant challenge for the regional authorities(Chartin et al., 2013; Yamada et al., 2015).

Although radiocesium sources have been extensively researched, less information is available in the literature regarding the fate of other radionuclides such as $\mathrm{U}$ or $\mathrm{Pu}$. Non-volatile $\mathrm{Pu}$ isotopes including ${ }^{239} \mathrm{Pu}\left(\mathrm{T}_{1 / 2}=24,110 \mathrm{y}\right.$, alpha-decay), ${ }^{240} \mathrm{Pu}\left(\mathrm{T}_{1 / 2}=6,563 \mathrm{y}\right.$, alpha-decay), ${ }^{241} \mathrm{Pu}\left(\mathrm{T}_{1 / 2}=14.35 \mathrm{y}\right.$, beta-decay) and ${ }^{242} \mathrm{Pu}\left(\mathrm{T}_{1 / 2}=376,000 \mathrm{y}\right.$, alpha-decay)(Evrard et al., 2014; Xu et al., 2016; Yamamoto et al., 2014; Zheng et al., 2012b) and $U$ isotopes including ${ }^{238} U\left(T_{1 / 2}=4.469 \times 10^{9} \mathrm{y}\right.$, alpha-decay $),{ }^{235} \mathrm{U}$ $\left(T_{1 / 2}=7.038 \times 10^{8} \mathrm{y}\right.$, alpha-decay), ${ }^{234} \cup\left(T_{1 / 2}=245,500 \mathrm{y}\right.$, alpha-decay $)$ and ${ }^{236} U\left(T_{1 / 2}=23.42 \times 10^{6} \mathrm{y}\right.$, alphadecay)(Sakaguchi et al., 2014; Schneider et al., 2017; Shinonaga et al., 2014; Yang et al., 2016), were also detected in environmental samples collected in the Fukushima Prefecture. These radionuclides may originate from two main sources: the global fallout associated with the nuclear atmospheric weapon tests(Yamamoto et al., 2014) and the FDNPP accident. Additionally, ${ }^{238} \mathrm{U},{ }^{235} \mathrm{U}$ and ${ }^{234} \mathrm{U}$ isotopes are naturally present in the environment. As $\mathrm{Pu}\left({ }^{240} \mathrm{Pu} /{ }^{239} \mathrm{Pu},{ }^{241} \mathrm{Pu} /{ }^{239} \mathrm{Pu}\right.$ and $\left.{ }^{242} \mathrm{Pu} /{ }^{239} \mathrm{Pu}\right)$ and $\mathrm{U}\left({ }^{236} \mathrm{U} /{ }^{238} \mathrm{U}\right)$ isotope ratios may vary significantly depending on their source(Muramatsu et al., 2003; Schneider et al., 2017), their precise measurement in sediment could provide powerful fingerprints for source identification. Accordingly, investigating the changes in the $\mathrm{Pu}$ and $\mathrm{U}$ signatures with depth in lacustrine sediment cores should provide information for reconstructing the changes in the respective contributions of these radionuclide sources in lacustrine sediment.

To the best of our knowledge, the analysis of $\mathrm{Pu}$ isotopes in continental sediment deposited in reservoirs following the FDNPP accident has been restricted to that of cores collected in the Lake Inba, located $200 \mathrm{~km}$ south of the FDNPP site (i.e. outside of the main radioactive plume)(Cao et al., 2017). Although the measured ${ }^{134} \mathrm{Cs} /{ }^{137} \mathrm{Cs}$ ratios indicated there was fallout from the FDNPP accident, 
the ${ }^{239+240} \mathrm{Pu}$ activity and the ${ }^{240} \mathrm{Pu} /{ }^{239} \mathrm{Pu}$ ratio remained similar to the global fallout signature, suggesting that FDNPP-derived Pu did not reach the Lake Inba basin in significant quantities.

In this study, the global fallout signature was first refined for the study region through the analysis of soil samples collected before the accident. Soils collected after the accident were analysed to characterise the initial spatial pattern of Pu deposited in this area and to compare it with the welldocumented ${ }^{137} \mathrm{Cs}$ deposition pattern. Then, the vertical distribution of $\mathrm{Pu}$ and $\mathrm{U}$ isotope ratios was characterised in a sediment core. These distributions were compared to that of ${ }^{137} \mathrm{Cs}$ concentrations measured in the core, and the contributions of the different sources of $\mathrm{Pu}$ in this region (global fallout vs. FDNPP) were quantified through the analysis of Pu isotope ratios. Implications regarding the fate and the geochemical behaviour of actinides in the catchments draining the main radioactive plume in the Fukushima Prefecture are then discussed.

\section{Materials and methods}

\section{Soil and sediment sampling}

In order to provide the local signature of the Pu global fallout in this region, four soil samples collected before the accident (in 2007 and in 2010, see Table S1) were first analysed. These samples were taken at two different locations in cultivated paddy fields $(12 \mathrm{~km}$ to the south-west of the Mano Dam, see Figure 1) and at two different depths (ploughed and underlying layers). To characterise the initial deposition of FDNPP-derived Pu, soil samples collected shortly after the accident (in November 2011, November 2012 and April 2012, see Table S2) were also analysed. Soil samples were taken from a range of ${ }^{137} \mathrm{Cs}$ fallout levels to be representative of potential FDNPP fallout (see Figure 1). Sampling methods are described elsewhere(Jaegler et al., 2018). In brief, soil samples are composed 
of 10 soil scrape subsamples, taken with a plastic trowel, that were thoroughly homogenized prior to analyses.

A sediment core collected in Lake Hayama, which is located $39 \mathrm{~km}$ to the northwest of the FDNPP in the Mano River catchment, was analysed. This lake corresponds to the artificial Mano Dam reservoir, with an area of $1.75 \mathrm{~km}^{2}$, a water volume of $36,200 \times 10^{3} \mathrm{~m}^{3}$ and a retention time of 0.48 year(Fukushima and Arai, 2014; Matsuda et al., 2015).

Researchers have investigated the radioactive contamination of sediment accumulated in this lake, although they restricted their analysis to radiocesium concentrations. Matsuda et al.(2015) measured the radiocesium concentration in bottom sediment and in lake water samples in 2012 and 2013, and they observed respective concentration decreases of $57 \%$ and $43 \%$ between the successive sampling campaigns. Huon et al.(2018) measured the vertical distribution of ${ }^{137} \mathrm{Cs}$ activities in four sediment cores sampled across the lake. Three of these four cores showed a distinct peak likely corresponding to the initial radiocesium wash-off and migration phase following the FDNPP accident. In the current study, one of these sediment cores (referred to as 'DD1') located in the downstream section of the lake and composed of fine sediment material(Huon et al., 2018) was selected to characterise variations of $\mathrm{Pu}$ and $\mathrm{U}$ isotope ratios with depth. More details on the core sampling and the radiocesium analyses are provided in Huon et al.(2018). In brief, the sediment core was collected on April 24, $2015\left(37^{\circ} 43^{\prime} 25.75^{\prime \prime} \mathrm{N}, 140^{\circ} 49^{\prime} 49.84^{\prime \prime E}\right)$ using a gravity core sampler, under approximately $45 \mathrm{~m}$ of water. The sediment core was $37 \mathrm{~cm}$ long and was then divided into 1 -cm increments from 0 to $15 \mathrm{~cm}$ depth, $2 \mathrm{~cm}$ from 15 to $25 \mathrm{~cm}$ depth and, finally, $3 \mathrm{~cm}$ from 25 to $37 \mathrm{~cm}$ depth. ${ }^{137}$ Cs content was measured by gamma spectrometry in each subsample in order to investigate the distribution of ${ }^{137} \mathrm{Cs}$ in the core(Huon et al., 2018). 


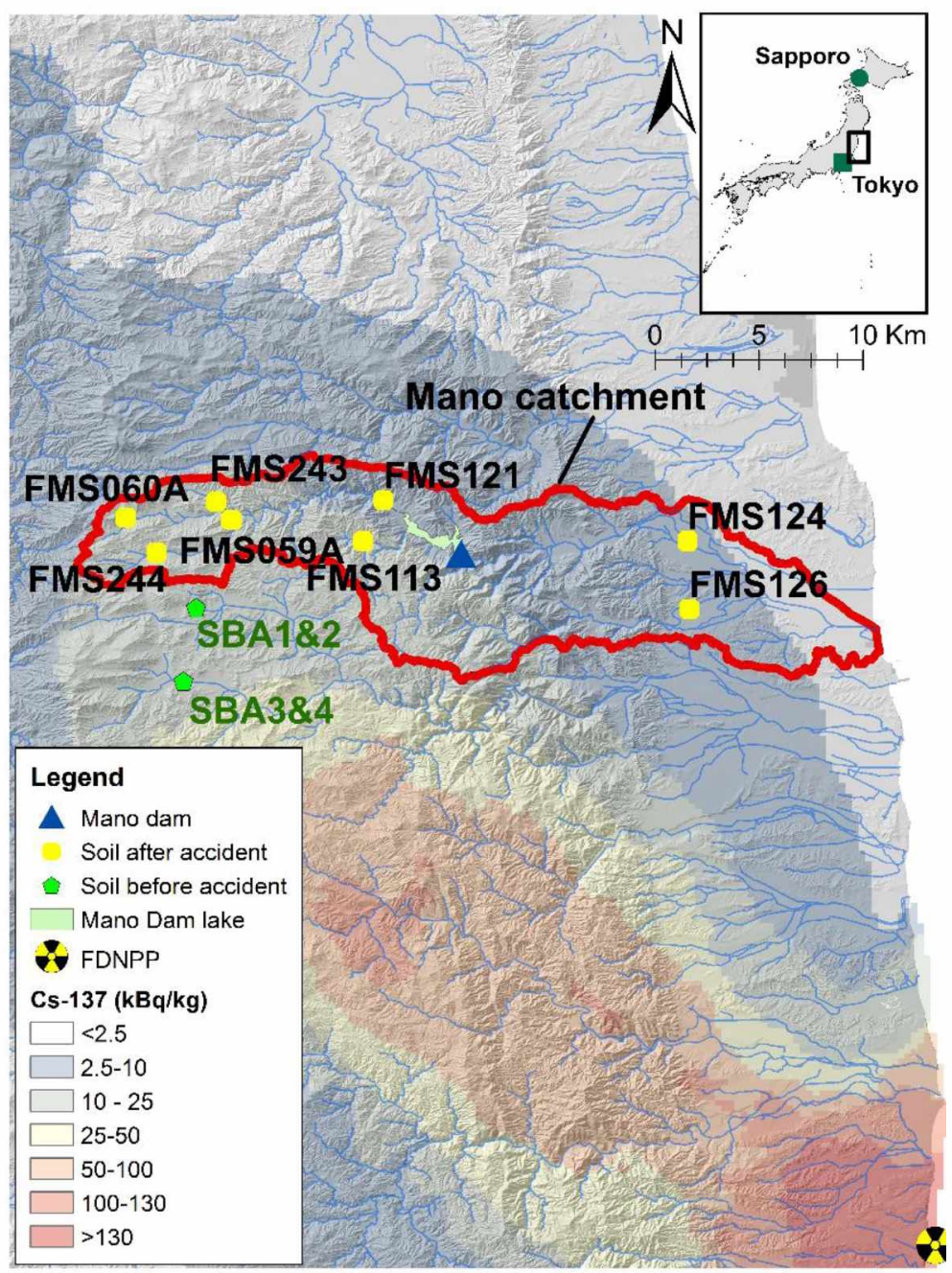

131 Figure 1: Location of the soil samples analysed in this current research in the Mano catchment delineated in red. The main radiocaesium contamination plume is also located in the background map derived from Chartin et al.(2013).

\section{Chemical preparation and separation of plutonium and uranium}

Core sections were grouped by pairs to provide sufficient material $(\sim 5 \mathrm{~g})$ for the actinide analyses.

Samples were placed in an electric furnace at $450{ }^{\circ} \mathrm{C}$ for $\sim 15 \mathrm{~h}$ to decompose the organic matter. After cooling to room temperature, they were transferred in Savillex ${ }^{\circledR}$ PFA Teflon ${ }^{\circledast}$ beakers. $~ 100 \mathrm{fg}$ of ${ }^{244} \mathrm{Pu}$ (diluted solution prepared from the certified isotopic reference material IRMM-042a, Geel, 
the samples was carried out through several acid leaching steps. Only partial dissolution protocol was performed as it was shown that this partial leaching was sufficient to dissolved actinide contained in samples(Lee et al., 2005,Liao, 2008 \#332,Jaegler, 2018 \#970). Moreover, total dissolution required use of concentrated $\mathrm{HF}$ acid, which is known to contain more impurities than concentrated $\mathrm{HCl}$ and $\mathrm{HNO}_{3}$ acid.

$50 \mathrm{~mL}$ concentrated $\mathrm{HNO}_{3}, 50 \mathrm{~mL}$ aqua regia and $50 \mathrm{~mL}$ concentrated $\mathrm{HCl}$. Between each leaching step, the solutions were dried in a closed evaporation system (Evapoclean ${ }^{\circledR}$, Analab, Hoenheim, France) at $110{ }^{\circ} \mathrm{C}$ until complete dryness. This device allows evaporation in a closed medium to prevent any lab contamination. Samples were then recovered with $2 \mathrm{M} \mathrm{HCl}$ and filtrated with a disposable $0.45 \mu \mathrm{m}$ Nalgene filtering unit (Thermo Scientific, Rochester, NY, USA). Dissolved fractions were transferred in clean Savillex ${ }^{\circledast}$ PFA Teflon ${ }^{\circledast}$ beakers and evaporated to dryness in closed media. Samples were then recovered with $50 \mathrm{~mL}$ of concentrated $\mathrm{HNO}_{3}$ and a few $\mathrm{mg}$ of $\mathrm{NaNO}_{2}$ were added to stabilize the (+IV) oxidation state of Pu and evaporated to dryness. Samples were finally recovered with $30 \mathrm{~mL}$ of $8 \mathrm{M} \mathrm{HNO}$ before Pu separation on chromatographic columns. The first column was composed of a Dowex AG1X8 anion-exchange resin filled with $\sim 10 \mathrm{~mL}$ of 50-100 mesh AG1X8 resin and $\sim 10 \mathrm{~mL}$ of $100-200$ mesh AG1X8 resin, conditioned with $8 \mathrm{M} \mathrm{HNO}_{3}$. After loading the sample onto the column, $\mathrm{U}$ was first eluted with $8 \mathrm{M} \mathrm{HNO}_{3}$. Then, Th was eliminated with $10 \mathrm{M} \mathrm{HCl}$. Pu was finally eluted with $\mathrm{NH}_{4} \mathrm{I}(1.5 \%)-12 \mathrm{M} \mathrm{HCl}$.

The same protocol was repeated twice on the Pu fraction with $2 \mathrm{~mL}$ Dowex AG1X4 anion-exchange resin (100-200 mesh) to reduce as much as possible sample matrix elements, which can potentially generate polyatomic (mainly $\left.\mathrm{PbO}_{2}{ }^{+},{ }^{238} \mathrm{UH}^{+}\right)$and isobaric $\left({ }^{241} \mathrm{Am}^{+}\right)$interferences. After evaporation of the eluate, samples were recovered and evaporated to dryness several times with concentrated $\mathrm{HNO}_{3}$ to eliminate chlorides. Finally, the last recovery was performed with $2 \% \mathrm{HNO}_{3}+0.01 \mathrm{M} \mathrm{HF}$ for ICP-MS measurements. The two consecutive purifications of the Pu fraction with Dowex resins allowed a complete elimination of $\mathrm{Am}$ (Trémillon, 1965). However, $\mathrm{PbO}_{2}^{+}$and $\mathrm{UH}^{+}$interferences persisted during ICP-MS measurements and required raw data corrections. The $U$ fraction collected 
with the first Dowex AG1X8 was further purified with a second column of $2 \mathrm{~mL}$ UTEVA extraction resin $(100-150 \mu \mathrm{m})$, conditioned with $4 \mathrm{M} \mathrm{HNO}_{3}$. U was directly eluted with $0.01 \mathrm{M} \mathrm{HNO}_{3}$. After evaporation to dryness of this eluted solution, the $U$ fraction of samples was finally recovered with $2 \% \mathrm{HNO}_{3}$ for ICP-MS measurements. At least two chemical blanks were systematically prepared with sample treatments. The sample preparation and $\mathrm{Pu}$ and $\mathrm{U}$ separation protocol efficiency was confirm by analysing certified reference materials in a previous study (Jaegler et al., 2018).

\section{Plutonium measurements by mass-spectrometry}

$\mathrm{Pu}$ isotopic composition in the samples were measured with a Multi-Collector Inductively Coupled Plasma Mass Spectrometer (MC-ICP-MS) (Neptune Plus, Thermo Fisher Scientific Inc., Bremen, Germany) equipped with eight Faraday cups and five ion counters for the simultaneous detection of ion beams. All measurements were performed using Aridus II (Cetac) as introduction system, highefficiency sampler and skimmer cones, reinforced pumping in the interface to enhance the sensitivity by a factor of $\sim 10$ (approximately $10^{8}$ counts $/ \mathrm{s}$ per $\mu \mathrm{g} / \mathrm{L}$ of ${ }^{238} \mathrm{U}$ ), compared to the standard configuration.

Two certified reference materials, IRMM 186 and IRMM 057 (both reference materials were provided by the Institute for Reference Materials and Measurements, Geel, Belgium), were measured on a regular basis throughout each analysis sequence and used to correct interferences and biases: instrumental mass fractionation, peak tailing at $M+1$ and $M+2$, and hydride formation (mainly ${ }^{238} \mathrm{UH}^{+}$) were determined. Lead polyatomic interferences $\left(\mathrm{PbO}_{2}{ }^{+}\right.$) were corrected by measuring three pure mono-elemental solutions of $\mathrm{Pb}$ at the end of the procedure. Measurement of these standards in the chemical blanks shows that main lead interferences are instrumental induced ( $\mathrm{PbAr})$ rather than induced by the chemical protocol $(\mathrm{PbCl})$. Moreover, as levels of interferences as similar in the blanks and in the sample, it shows that $\mathrm{Pb}$ is originating from the reagents added during radiochemical protocol and not contained in the sample. All these corrections were applied to a 
solution of the Pu isotopic certified material CRM128 (NBL, US DOE) for verification. Finally, all Pu compositions were corrected for tracer impurities according to the certificate of the isotopic reference material IRMM-042a, decay-corrected to March 15, 2011 and for blank levels (average of total Pu in the blanks: $3.4 \pm 1.2 \mathrm{fg}$ ).

\section{Uranium measurements by mass spectrometry}

Precise ${ }^{236} \mathrm{U}$ measurements were performed twice in two different laboratories: at CEA/LANIE (“Commissariat à l’Energie Atomique et aux Energies Alternatives/ Laboratoire de développement Analytique Nucléaire, Isotopique, Elémentaire") and at IRSN/LELI ("Institut de Radioprotection et de Sureté du Nucléaire ( Laboratoire sur le devenir des pollutions des sites radioactifs") using two ICPMS/MS (Agilent 8800, Agilent Technologies, Tokyo, Japan) instruments well-suited for the measurement of extremely low ${ }^{236} \mathrm{U} /{ }^{238} \mathrm{U}$ isotope ratios(Tanimizu et al., 2013; Yang et al., 2016). Two analyses on each sample were conducted to provide more confidence in the results. The strategy followed in both laboratories was based on the mass shift mode (through the detection of the oxide form, $\left.\mathrm{U}^{16} \mathrm{O}^{+}\right)$as described by Tanimizu et al. and Yang et al.(2013; 2016). This strategy allowed for reducing ${ }^{238} \mathrm{U}$ and ${ }^{235} \mathrm{U}$ peak tailing and hydride formation from ${ }^{235} \mathrm{U}$ at $\mathrm{m} / \mathrm{z}=236$ opening up the possibility to measure very low ${ }^{236} \mathrm{U} /{ }^{238} \mathrm{U}$ isotope ratios. Owing to these strong interferences, the measurement of very low ${ }^{236} \mathrm{U} /{ }^{238} \mathrm{U}$ ratios by MC-ICP-MS is limited.

Both laboratories are equipped with the same ICP-MS/MS instrument and used desolvating introduction systems in order to increase sensitivity and to reduce the formation of hydrides. However, desolvating devices and measurement procedures showed significant differences.

The LANIE laboratory used the Aridus (Cetac Technologies, Omaha, NE, USA) introduction system. The ${ }^{236} \mathrm{U} /{ }^{238} \mathrm{U}$ in the samples was deduced through the measurement of ${ }^{236} \mathrm{UO}^{+} /{ }^{235} \mathrm{UO}^{+}$using the natural ${ }^{238} \mathrm{U} /{ }^{235} \mathrm{U}\left(137.88\right.$ ) ratio (as ${ }^{238} \mathrm{U}$ and ${ }^{235} \mathrm{U}$ are mostly originating from natural uranium). 
${ }^{236} \mathrm{UO}^{+} /{ }^{235} \mathrm{UO}^{+}$ratio was corrected for hydride formation $\left({ }^{235} \mathrm{UOH}^{+} /{ }^{235} \mathrm{UO}^{+}\right)$and for the chemical blanks. The instrumental mass fractionation was internally corrected using the ${ }^{234} \mathrm{UO}^{+} /{ }^{235} \mathrm{UO}^{+}$ratios of the samples, compared with the ${ }^{234} \mathrm{U} /{ }^{235} \mathrm{U}$ isotope ratio also determined with another ICP-MS instrument.

The LELI laboratory used the Apex-HF (Elemental Scientific, Omaha, NE, USA) introduction system. In order to acquire signals only with the pulse counting mode during the analysis, the ${ }^{236} \mathrm{UO}^{+} /{ }^{235} \mathrm{UO}^{+}$ ratio was measured and the ${ }^{236} \mathrm{U} /{ }^{238} \mathrm{U}$ was deduced using the natural ${ }^{238} \mathrm{U} /{ }^{235} \mathrm{U}$ (137.88) ratio. Instrumental mass fractionation was corrected by a standard bracketing method using the measured ${ }^{234} \mathrm{U} /{ }^{235} \mathrm{U}$ ratio of an IRMM186 certified solution. A hydride correction factor was calculated using the ${ }^{238} \mathrm{UOH}^{+} /\left({ }^{235} \mathrm{UO}^{+} \times 137.88\right)$ ratio and applied to the ${ }^{236} \mathrm{U}$ measurements to correct for the ${ }^{235} \mathrm{UO}^{+}$ hydride formation.

\section{$\mathrm{Pu}$ and $\mathrm{U}$ source term signatures}

Pu deposition on soils of this region may originate from two main sources: the global fallout and the FDNPP accident. Pu fuel isotopic compositions at the moment of the accident were estimated to be $0.373 \pm 0.044(2 \sigma)$ for ${ }^{240} \mathrm{Pu} /{ }^{239} \mathrm{Pu}, 0.1874 \pm 0.0081(2 \sigma)$ for ${ }^{241} \mathrm{Pu} /{ }^{239} \mathrm{Pu}$, and $0.0637 \pm 0.0026(2 \sigma)$ for ${ }^{242} \mathrm{Pu} /{ }^{239} \mathrm{Pu}$ (Kirchner et al., 2012; Nishihara et al., 2012; Schwantes et al., 2012).

The global fallout signatures provided in the literature were measured worldwide(Kelley et al., 1999) including various locations across Japan(Momoshima et al., 1997; Muramatsu et al., 2003; Ohtsuka et al., 2004; Zhang et al., 2010). As the range of these Pu signatures is relatively wide (Table S3), there is a need to refine the global fallout signatures for this specific sampling location in the Fukushima Prefecture. In this study, the measurements conducted on the bottom sediment sample layer in the core and on the soil samples collected before the accident were used to provide the local signatures of the global fallout. 
Unlike $\mathrm{Pu}, \mathrm{U}$ is also naturally present in the environment with two primordial isotopes $\left({ }^{238} \mathrm{U}\right.$ and $\left.{ }^{235} \mathrm{U}\right)$

243 and one radiogenic isotope $\left({ }^{234} \mathrm{U}\right)$ originating from the ${ }^{238} \mathrm{U}$-decay. Moreover, these isotopes are

244 relatively abundant in soils and sediment, with the $U$ concentration being 6 to 9 orders of magnitude

245 higher than that of $\mathrm{Pu}\left(\mathrm{Bu}\right.$ et al., 2017). On the contrary, the ${ }^{236} \mathrm{U}$ isotope has an extremely low

246 abundance in natural-occurring $U$ present in environmental samples $\left(<10^{-13}\right)$. However, ${ }^{236} \mathrm{U}$ is also

247 produced in significant quantities in nuclear reactors (by the capture of a neutron by the fissile

248 nuclide ${ }^{235} \mathrm{U}$ ), which may result in ${ }^{236} \mathrm{U} /{ }^{238} \mathrm{U}$ ratios locally higher in those samples collected in the

249 close vicinity of some nuclear installations. For the $U$ ratio representative of the FDNPP signature,

250 only Nishihara et al.(2012) estimated the ${ }^{236} \mathrm{U} /{ }^{238} \mathrm{U}$ in the nuclear fuel ratio at the time of the 251 accident, being $(3.20-3.71) \times 10^{-3}\left(\operatorname{mean}(3.42 \pm 0.52) \times 10^{-3}, 2 \sigma\right)$. Nevertheless, the main 252 contribution of ${ }^{236} \mathrm{U}$ in soils is, as for $\mathrm{Pu}$ isotopes, the global fallout associated with the nuclear 253 weapon atmospheric tests.

254 The representative ${ }^{236} \mathrm{U} /{ }^{238} \mathrm{U}$ ratios for the global fallout signature in Japan were previously measured 255 in a soil core $(n=3)$ sampled in the Ishikawa Prefecture(Sakaguchi et al., 2009$)\left(1.85 \times 10^{-8}-1.09 \times 10^{-7}\right.$, 256 mean $\left.(5.31 \pm 0.12) \times 10^{-8}, 2 \sigma\right)$. However, Schneider et al.(2017) recently determined even lower ${ }^{236} \mathrm{U} /{ }^{238} \mathrm{U}$ ratios in the range of $10^{-9}$ in soil samples collected at various locations within the exclusion zone nearby the FDNPP, and reported this signature as that of 'undisturbed uranium'. Currently, this ratio remains poorly constrained with values varying between $10^{-10}$ and $10^{-7}$.

The potential occurrence of $U$ contamination following the FDNPP accident in the environment has been examined in very few studies(Sakaguchi et al., 2014; Schneider et al., 2017; Shinonaga et al., 2014; Yang et al., 2016) (See Table S4). Most of these samples reported ${ }^{236} \mathrm{U} /{ }^{238} \mathrm{U}$ ratios between $10^{-8}$ and $10^{-7}$, which suggests a global fallout origin(Sakaguchi et al., 2010). Shinonaga et al.(2014) measured ratios of $10^{-6}$ in aerosol filter samples collected at $120 \mathrm{~km}$ from the FDNPP shortly after the accident. However, as early as in April $2011 \mathrm{U}$ ratios measured in aerosols collected at the same amounts during the FDNPP accident. 
269 Accordingly, in the current research, the $U$ isotope compositions were only analysed in the sediment core, as the soil erosion and sediment transport processes are known to be selective and to mobilize

271 preferentially the finest and most contaminated particles(Evrard et al., 2015; Laceby et al., 2017).

272 Furthermore, ${ }^{236} \mathrm{U}$ concentrations in the soil samples collected before and after the accident would likely be too low to be detectable by ICP-MS with the chemical processes followed in this study.

\section{Quantifying source contributions}

The proportions of each source of Pu were determined using a binary mixing model(Kelley et al.,

1999). To this end, the isotopic abundance of ${ }^{241} \mathrm{Pu}$ in each source term and in each sediment sample and each soil sample collected after the accident was calculated. ${ }^{241} \mathrm{Pu}$ abundance was used owing to its relatively short half-life resulting in this isotope providing the best discrimination between emissions from the global fallout or the FDNPP accident. Atomic abundance of each term $\mathrm{Ab}\left({ }^{241} \mathrm{Pu}\right)_{\text {sample }} \mathrm{Ab}\left({ }^{241} \mathrm{Pu}\right)_{\mathrm{GF}}$ or $\mathrm{Ab}\left({ }^{241} \mathrm{Pu}\right)_{\mathrm{FDNPP}}$ is given in Equation 1 :

$$
A b\left({ }^{241} \mathrm{Pu}\right)_{i}=\frac{\left({ }^{241} \mathrm{Pu} /{ }^{239} \mathrm{Pu}\right)_{i}}{1+\left({ }^{240} \mathrm{Pu} /{ }^{239} \mathrm{Pu}\right)_{i}+\left({ }^{241} \mathrm{Pu} /{ }^{239} \mathrm{Pu}\right)_{i}+\left({ }^{242} \mathrm{Pu} /{ }^{239} \mathrm{Pu}\right)_{i}}
$$

where $i$ stands for "sample" or "GF" or "FDNPP".

Abundance for FDNPP source $A b\left({ }^{241} \mathrm{Pu}\right)_{\text {FDNPP }}$ as estimated at $(1.15 \pm 0.12) \times 10^{-2}$ based on results published by Nishihara et al.(2012), Kirchner et al.(2012) and Schwantes et al.(2012). Other endmember abundances were derived from our measurements. Then, the proportions of each source term were deduced using a mixing equation with two sources (Equation 2):

$$
\mathrm{Ab}\left({ }^{241} \mathrm{Pu}\right)_{\mathrm{FDNPP}} \times \mathrm{X}_{\mathrm{FDNPP}}+\mathrm{Ab}\left({ }^{241} \mathrm{Pu}\right)_{\mathrm{GF}} \times\left(1-\mathrm{X}_{\mathrm{FDNPP}}\right)=\mathrm{Ab}\left({ }^{241} \mathrm{Pu}\right)_{\text {sample }}
$$



3):

$$
\mathrm{X}_{\mathrm{FDNPP}}=\frac{\left({ }^{239} \mathrm{Pu}+{ }^{240} \mathrm{Pu}+{ }^{241} \mathrm{Pu}+{ }^{242} \mathrm{Pu}\right)_{\mathrm{FDNPP}}}{\left({ }^{239} \mathrm{Pu}+{ }^{240} \mathrm{Pu}+{ }^{241} \mathrm{Pu}+{ }^{242} \mathrm{Pu}\right)_{\text {sample }}}
$$

These proportions, based on the atomic ratio, were converted into mass proportions to determine the Pu concentrations originating from the FDNPP relative to those derived from the global fallout. Although no source contribution could be modelled for $U$, theoretical ${ }^{236} U$ concentrations released from the FDNPP were estimated based on the results of plutonium concentrations found in the samples analysed in the current research. First, the corresponding theoretical ${ }^{236} \mathrm{U} /\left({ }^{239} \mathrm{Pu}+{ }^{240} \mathrm{Pu}+{ }^{241} \mathrm{Pu}+{ }^{242} \mathrm{Pu}\right)$ isotope ratios were estimated to be $0.46 \pm 0.12(2 \sigma)$ (Nishihara et al.

$\underline{2012)}$, based on literature data. Then, the concentration of FDNPP-derived ${ }^{236} U\left({ }^{236} U_{\text {FDNPP }}\right)$ was estimated based on the estimations of the FDNPP-derived Pu concentrations found in the soil samples, and compared with the global fallout derived ${ }^{236} \mathrm{U}$ concentration.

\section{Results and discussion}

Refining the Pu global fallout signature in soils and sediment of the Fukushima Prefecture

In the sediment core collected in the Hayama Lake, the ${ }^{240} \mathrm{Pu} /{ }^{239} \mathrm{Pu},{ }^{241} \mathrm{Pu} /{ }^{239} \mathrm{Pu}$ and the ${ }^{242} \mathrm{Pu} /{ }^{239} \mathrm{Pu}$ isotope ratios measured in the bottom layer $(31 \mathrm{~cm}, \mathrm{MD} 7)$ were within the range of values for the global fallout reported in the literature. Accordingly, it is assumed that these actinides in the bottom layer of the core were likely supplied by the global fallout. 
values previously published in the literature, particularly for the ${ }^{241} \mathrm{Pu} /{ }^{239} \mathrm{Pu}$ ratio, which ranged from 0.0023 to 0.0117 (mean $0.0061 \pm 0.0010,2 \sigma$ ). The relative proximity of the sites where Chinese nuclear weapons were tested between 1964 and 1980 may have resulted in these high values. However, the maximum ${ }^{241} \mathrm{Pu} /{ }^{239+240} \mathrm{Pu}$ activity ratio measured in the current study is $61 \pm 12$ (SBA2, decay-corrected to the date of the main test on November 17, 1976), which is higher than that measured in the Chinese test debris (11 according to Zhang et al.,.2010) and Hirose et al..(2001)). More research is required to investigate these high pre-FDNPP accident plutonium isotope ratio values and their heterogeneity.

319 Table 1: ${ }^{137} \mathrm{Cs}$ activities and $\mathrm{Pu}$ isotope ratios measured in the soil samples collected before the accident. ${ }^{241} \mathrm{Pu} /{ }^{239} \mathrm{Pu}$ is decay-corrected to March 15,2011 . Uncertainties are extended with a coverage factor of 2.

\begin{tabular}{|c|c|c|c|c|c|c|c|c|c|c|c|c|c|}
\hline $\begin{array}{l}\text { Sample } \\
\text { label }\end{array}$ & ${ }^{137} \mathrm{C}$ & $(\mathrm{Bq} / \mathrm{kg})$ & ${ }^{240} \mathrm{Pu} /$ & & & ${ }^{241} \mathrm{Pu} / /^{239}$ & & & ${ }^{242} \mathrm{Pu} /{ }^{239} \mathrm{~F}$ & & & $\begin{array}{l}\mathrm{Pu} \\
\text { conce } \\
\text { (fg/g) }\end{array}$ & tration \\
\hline SBA1 & 5.0 & \pm 1.4 & 0.182 & \pm & 0.012 & 0.0044 & \pm & 0.0017 & 0.0056 & \pm & 0.0010 & 48.1 & \pm 5.9 \\
\hline SBA2 & 3.7 & \pm 0.8 & 0.179 & \pm & 0.007 & 0.0117 & \pm & 0.0023 & 0.0071 & \pm & 0.0006 & 29.5 & \pm 1.1 \\
\hline SBA3 & 3.1 & \pm 1.2 & 0.179 & \pm & 0.013 & 0.0023 & \pm & 0.0005 & 0.0052 & \pm & 0.0013 & 22.4 & \pm 1.8 \\
\hline SBA4 & & $<2.8$ & & - & & & - & & & - & & & $<0.5$ \\
\hline
\end{tabular}

322 To model the source contributions of $\mathrm{Pu}$ in the samples, the Pu isotope ratios characterising the local 323 signature of the global fallout in the Mano River catchment was calculated based on those results 324 obtained for samples exposed only to the global fallout: the pre-accident soil samples (SBA1, SBA2 and SBA3) and the bottom layer of the sediment core (MD7). Accordingly, the mean plutonium isotope ratios characterising the global fallout signature in the study area are: ${ }^{240} \mathrm{Pu} /{ }^{239} \mathrm{Pu}=0.180 \pm$ $0.010 ;{ }^{241} \mathrm{Pu} /{ }^{239} \mathrm{Pu}=0.0052 \pm 0.0017$ and ${ }^{242} \mathrm{Pu} /{ }^{239} \mathrm{Pu}=0.0054 \pm 0.0022$ (uncertainties are extended with a coverage factor of 2.) 
$332 \mathrm{Pu}$ isotope ratios were measured in eight soil samples collected in the catchment after the accident

333 (Table 2). Results showed that $\mathrm{Pu}$ isotope ratios remained generally close to the global fallout 334 signature: the atomic proportions of Pu from the FDNPP in these soils were estimated to be lower 335 than $7 \%$ (see Table 2, Table S5). Sample FMS243 provides an exception to this rule, as it contained more than $40 \%$ of $\mathrm{Pu}$ from the power plant. On the contrary, low isotope ratios were measured in 337 sample FMS113, in particular the ${ }^{240} \mathrm{Pu} /{ }^{239} \mathrm{Pu}$ isotope ratio $(0.160 \pm 0.011)$. The relevance of this value 338 is confirmed by the measurement of similar ratios in Japanese soils: Muramatsu et al.(2003) 339 observed a ratio of $0.155 \pm 0.003$ in a forest soil sample collected before 2002, and Zheng et $340 a l .(2012 \mathrm{~b})$ found a ratio of $0.144 \pm 0.006$ in a soil sample collected in 2011 at $32 \mathrm{~km}$ from the FDNPP. 341 Moreover, no correlation $(p<0.001)$ could be observed between ${ }^{137} \mathrm{Cs}$ activities and $\mathrm{Pu}$ isotope ratios 342 in these samples. This confirms that Pu deposition on soils was locally heterogeneous(Salbu, 2011 ; 343 Schneider et al., 2013). It may also reflect the occurrence of different processes of aerial transport of 344 radiocesium and Pu from the FDNPP to the study area. 

with a coverage factor of 2 .

\begin{tabular}{|c|c|c|c|c|c|c|c|c|c|c|c|c|c|c|}
\hline \multirow{2}{*}{$\begin{array}{l}\text { Sample label } \\
\text { FMS059A }\end{array}$} & \multicolumn{2}{|c|}{${ }^{137} \mathrm{Cs}(\mathrm{kBq} / \mathrm{kg})$} & \multicolumn{3}{|c|}{${ }^{240} \mathrm{Pu} /{ }^{239} \mathrm{Pu}$} & \multicolumn{2}{|c|}{${ }^{241} \mathrm{Pu} /{ }^{239} \mathrm{Pu}$} & \multicolumn{3}{|c|}{${ }^{242} \mathrm{Pu} /{ }^{239} \mathrm{Pu}$} & \multicolumn{2}{|c|}{$\begin{array}{l}\mathrm{Pu} \\
\text { concentration } \\
\text { (fg/g) }\end{array}$} & \multicolumn{2}{|c|}{$\begin{array}{l}\text { Fraction of } \mathrm{Pu} \\
\text { from FDNPP (\%) }\end{array}$} \\
\hline & 18.70 & \pm 0.94 & 0.177 & \pm & 0.014 & 0.0033 & \pm 0.0017 & 0.0048 & \pm & 0.0019 & 112.1 & \pm 6.1 & 1.4 & \pm 1.2 \\
\hline FMS060A & 30.59 & \pm 1.50 & 0.184 & \pm & 0.017 & 0.0075 & \pm 0.0045 & 0.0059 & \pm & 0.0016 & 45.8 & \pm 3.9 & 4.4 & \pm 3.3 \\
\hline FMS243 & 19.40 & \pm 0.97 & 0.285 & \pm & 0.049 & 0.0666 & \pm 0.0178 & 0.0488 & \pm & 0.0029 & 75.6 & \pm 9.6 & 40.6 & \pm 11.4 \\
\hline FMS244 & 65.72 & \pm 3.30 & 0.188 & \pm & 0.019 & 0.0069 & \pm 0.0009 & 0.0057 & \pm & 0.0010 & 78.4 & \pm 6.0 & 3.9 & \pm 0.8 \\
\hline FMS113 & 13.37 & \pm 0.67 & 0.160 & \pm & 0.011 & 0.0058 & \pm 0.0018 & 0.0075 & \pm & 0.0029 & 61.0 & \pm 6.2 & 3.2 & \pm 1.4 \\
\hline FMS121 & 0.19 & \pm 0.01 & 0.184 & \pm & 0.011 & 0.0027 & \pm 0.0017 & 0.0057 & \pm & 0.0007 & 48.0 & \pm 3.5 & 0.9 & \pm 1.3 \\
\hline FMS124 & 3.28 & \pm 0.16 & 0.197 & \pm & 0.013 & 0.0113 & \pm 0.0062 & 0.0116 & \pm & 0.0008 & 67.4 & \pm 5.4 & 7.0 & \pm 4.5 \\
\hline FMS126 & 0.84 & $\pm \quad 0.04$ & 0.187 & \pm & 0.016 & 0.0094 & \pm 0.0010 & 0.0124 & \pm & 0.0022 & 26.1 & \pm 2.0 & 5.7 & \pm 1.0 \\
\hline
\end{tabular}

347 
351 The ${ }^{137} \mathrm{Cs}$ activities in the sediment core demonstrated that the lowest activity (mean $=0.58 \pm 0.03 \mathrm{~Bq} / \mathrm{g}$ ) 352 was found in the bottom of the core (at $31-37 \mathrm{~cm}$ depth). The maximum activity was observed at $11-$ $35312 \mathrm{~cm}(40.24 \pm 2.01 \mathrm{~Bq} / \mathrm{g})$ before decreasing in the upper part of the core (at $0-7 \mathrm{~cm}$ depth) to a mean of $35416.96 \pm 0.85 \mathrm{~Bq} / \mathrm{g}$ (Table 3 ). The maximum of activity corresponds to the deposition of strongly 355 contaminated sediment in the reservoir shortly after the FDNPP accident. This increase of the activity 356 likely reflects the radiocesium wash-off and migration phase during the six first months that followed the 357 FDNPP accident(Huon et al., 2018). 
359 Table $3:{ }^{137} \mathrm{Cs}$ activities and $\mathrm{Pu}$ isotope ratios and Pu concentrations measured in the Mano Dam sediment core.

360 Uncertainties are extended with a coverage factor of 2.

\begin{tabular}{|c|c|c|c|c|c|c|c|c|c|c|c|c|c|c|c|}
\hline $\begin{array}{c}\text { Sample } \\
\text { depth } \\
(\mathrm{cm})\end{array}$ & $\begin{array}{c}\text { Sample } \\
\text { ID }\end{array}$ & \multicolumn{3}{|c|}{${ }^{137} \mathrm{Cs}(\mathrm{kBq} / \mathrm{kg})$} & \multicolumn{3}{|c|}{${ }^{240} \mathrm{Pu} /{ }^{239} \mathrm{Pu}$} & \multicolumn{3}{|c|}{${ }^{241} \mathrm{Pu} /{ }^{239} \mathrm{Pu}$} & \multicolumn{3}{|c|}{${ }^{242} \mathrm{Pu} /{ }^{239} \mathrm{Pu}$} & \multicolumn{2}{|c|}{$\begin{array}{c}\mathrm{Pu} \\
\text { concentration } \\
(\mathrm{fg} / \mathrm{g})\end{array}$} \\
\hline $0-1$ & \multirow{2}{*}{ MD1 } & 19.67 & \pm & 0.98 & \multirow{2}{*}{0.180} & \multirow{2}{*}{ \pm} & \multirow{2}{*}{0.002} & \multirow{2}{*}{0.0038} & \multirow{2}{*}{ \pm} & \multirow{2}{*}{0.0007} & \multirow{2}{*}{0.0043} & \multirow{2}{*}{ \pm} & \multirow{2}{*}{0.0003} & \multirow{2}{*}{155.5} & \multirow{2}{*}{ \pm 11.3} \\
\hline $1-2$ & & 18.27 & \pm & 0.91 & & & & & & & & & & & \\
\hline $2-3$ & - & 17.77 & \pm & 0.89 & & - & & & - & & & - & & & - \\
\hline $3-4$ & - & 15.99 & \pm & 0.80 & & - & & & - & & & - & & & - \\
\hline $4-5$ & - & 15.39 & \pm & 0.77 & & - & & & - & & & - & & & - \\
\hline $5-6$ & \multirow{2}{*}{ MD2 } & 15.31 & \pm & 0.77 & \multirow{2}{*}{0.172} & \multirow{2}{*}{ \pm} & \multirow{2}{*}{0.002} & \multirow{2}{*}{0.0045} & \multirow{2}{*}{ \pm} & \multirow{2}{*}{0.0008} & \multirow{2}{*}{\multicolumn{2}{|c|}{0.0060}} & & \multirow{2}{*}{233.8} & \multirow{2}{*}{ \pm 21.0} \\
\hline $6-7$ & & 16.35 & \pm & 0.82 & & & & & & & & & & & \\
\hline $7-8$ & \multirow{2}{*}{ MD3 } & 21.06 & \pm & 1.05 & 0.174 & & 0.002 & 00033 & + & 00007 & 0,0042 & & 0,0003 & 1703 & \\
\hline $8-9$ & & 26.55 & \pm & 1.33 & $0.1 / 4$ & \pm & 0.002 & 0.0033 & \pm & 0.0007 & 0.0042 & \pm & 0.0003 & $1 / 0.3$ & $\pm<5.3$ \\
\hline $9-10$ & MD4 & 31.76 & \pm & 1.59 & 181 & + & רחת ח & 00060 & + & ר 100 & 00050 & + & 00005 & 1230 & \\
\hline $10-11$ & IVID4 & 31.23 & \pm & 1.56 & 0.184 & \pm & 0.002 & 0.0060 & \pm & 0.0012 & 0.0054 & \pm & 0.0005 & 123.0 & \pm 12.0 \\
\hline $11-12$ & MD5 & 40.24 & \pm & 2.01 & 0182 & + & בחח & 0 & + & 00011 & בחח 0 & + & בחחم & 775 & \\
\hline $12-13$ & IVIDS & 31.43 & \pm & 1.57 & 0.182 & \pm & 0.002 & 0.0080 & \pm & 0.0011 & 0.0002 & \pm & 0.0003 & 17.3 & $\pm 1<.1$ \\
\hline $13-14$ & - & 15.22 & \pm & 0.76 & & - & & & - & & & - & & & - \\
\hline $14-15$ & - & 7.91 & \pm & 0.40 & & - & & & - & & & - & & & - \\
\hline $15-17$ & MD6 & 2.64 & \pm & 0.13 & 0159 & + & ( $\cap \cap \cap$ & 00015 & + & $0 \cap 0 \cap 4$ & $0 \cap 034$ & + & 00005 & 1 & +325 \\
\hline $17-19$ & IVIUO & 0.99 & \pm & 0.05 & 0.139 & $I$ & 0.001 & 0.0010 & $I$ & 0.0004 & 0.0054 & $I$ & 0.0000 & 209.1 & I $3<.0$ \\
\hline $19-21$ & - & 0.81 & \pm & 0.04 & & - & & & - & & & - & & & - \\
\hline $21-23$ & - & 0.88 & \pm & 0.04 & & - & & & - & & & - & & & - \\
\hline $23-25$ & - & 0.77 & \pm & 0.04 & & - & & & - & & & - & & & - \\
\hline $25-28$ & - & 0.48 & \pm & 0.02 & & - & & & - & & & - & & & - \\
\hline $28-31$ & - & 0.24 & \pm & 0.01 & & - & & & - & & & - & & & - \\
\hline $31-34$ & & 0.29 & \pm & 0.01 & & & & & & & & & & & \\
\hline $34-37$ & MD7 & 0.21 & \pm & 0.01 & 0.175 & \pm & 0.002 & 0.0022 & \pm & 0.0008 & 0.0037 & \pm & 0.0003 & 84.1 & \pm 11.4 \\
\hline
\end{tabular}

362 Change of plutonium isotopic composition with depth

364 The evolution of the Pu isotopic composition with depth showed a similar pattern as ${ }^{137} \mathrm{Cs}$ activity (see

365 Table 3 and Figure 2). All isotope ratios $\left({ }^{240} \mathrm{Pu} /{ }^{239} \mathrm{Pu},{ }^{241} \mathrm{Pu} /{ }^{239} \mathrm{Pu}\right.$ and $\left.{ }^{242} \mathrm{Pu} /{ }^{239} \mathrm{Pu}\right)$ had a low value at the 366 bottom of the core. Then, all ratios increased up to maximum values found at $11-12 \mathrm{~cm}$ depth, which 367 corresponds to the peak in the ${ }^{137} \mathrm{Cs}$ activity. The variations on the sediment core with depth clearly 
reflect changes in the origin of Pu(Evrard et al., 2014; Jaegler et al., 2018), ranging between the global

fallout signature and the FDNPP signature (see Figure S1), with the exception of the ${ }^{240} \mathrm{Pu} /{ }^{239} \mathrm{Pu}$ isotope ratio measured in one sample (see below).

372 For ${ }^{240} \mathrm{Pu} /{ }^{239} \mathrm{Pu}$ ratios, all values remained in the range of the global fallout (Figure 2) although the 373 highest ratios corresponded to the maximum ${ }^{137} \mathrm{Cs}$ activity observed in the $11-12 \mathrm{~cm}$ depth layer. A 374 surprisingly low ratio value of $0.159 \pm 0.001$ was found in the layer MD6 ( $15-19 \mathrm{~cm}$ depth). Similar ratios 375 lower than or equal to 0.16 were previously reported in Japan: Muramatsu et al.(2003) and Zheng et $376 a l . \underline{(2012 b)}$, and Evrard et al.(2014), who measured a ratio of $0.150 \pm 0.005$ in a sediment sample 377 collected in 2012. For those ${ }^{241} \mathrm{Pu} /{ }^{239} \mathrm{Pu}$ atom ratios, all isotope ratios measured in sediment samples 378 collected between 0 and $10 \mathrm{~cm}$ depth in the core were significantly higher than the upper limit of the 379 global fallout signature updated in the current study, showing a clear influence of the FDNPP inputs. A 380 good correlation was observed between this ratio in particular and the ${ }^{137} \mathrm{Cs}$ activities (correlation 381 coefficient of $0.90, p$-value $<0.001)$. Finally, when examining ${ }^{242} \mathrm{Pu} /{ }^{239} \mathrm{Pu}$ values, they were slightly higher 382 than the upper limit of the global fallout, demonstrating a very low, although clear, impact of the FDNPP 383 fallout. 


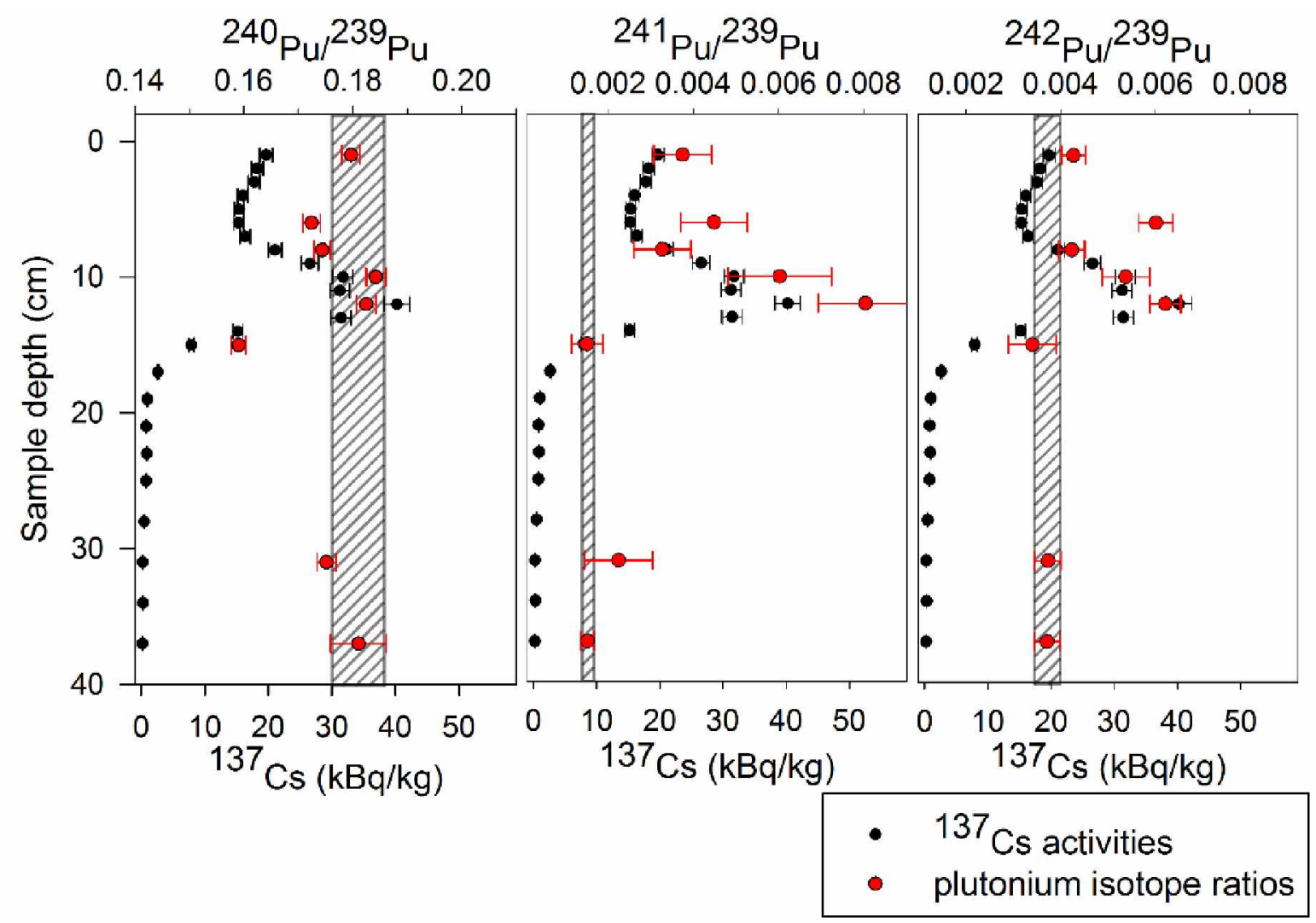

Figure 2: Evolution of ${ }^{137} \mathrm{Cs}$ activities (black dots), ${ }^{240} \mathrm{Pu} /{ }^{239} \mathrm{Pu},{ }^{241} \mathrm{Pu} /{ }^{239} \mathrm{Pu}$ and ${ }^{242} \mathrm{Pu} /{ }^{239} \mathrm{Pu}$ atom ratios (red dots) with depth in the Mano Dam sediment core. The dashed zones provide the corresponding range of values reported for

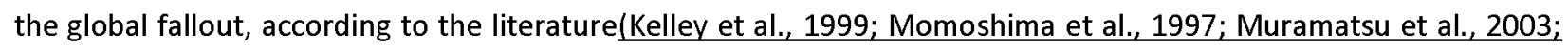
Ohtsuka et al., 2004; Zhang et al., 2010). Uncertainties are extended with a coverage factor of 2.

The maximum isotope ratio (MD5) corresponded to a maximum FDNPP atomic contribution estimated to be $4.3 \pm 1.0 \%$. The measurement conducted on the deeper MD6 sediment layer showed the absence of contribution from FDNPP $(0.0 \pm 0.7 \%)$. This result suggested that the migration of Pu with depth in the sediment profile was negligible. 
Although detectable, the release of Pu from the FDNPP remained low in the sediment accumulated in the Mano Dam (Table S6). Accordingly, the Pu detected in the sediment samples was mainly supplied by the global fallout.

The shape of the three $\mathrm{Pu}$ isotopes profiles shows the occurrence of large variations, which were not observed for the ${ }^{137} \mathrm{Cs}$ activity profile. No correlation $(p=0.015)$ was found between ${ }^{137} \mathrm{Cs}$ and $\mathrm{Pu}$ 402 concentrations, as the main source that supplied these two radionuclides strongly differed: ${ }^{137} \mathrm{Cs}$ was mainly supplied by the FDNPP releases, whereas Pu mainly originated from the global fallout. The variations of $\mathrm{Pu}$ in the core likely reflect the heterogeneity of the $\mathrm{Pu}$ isotope ratios derived from the global fallout as the global fallout Pu concentration was shown to be strongly heterogeneous $\underline{\underline{(K e l l e y ~ e t}}$ al., 1999) due to the particulate form of deposition(Salbu, 2011).

\section{Evolution of the ${ }^{236} \mathrm{U}$ isotopic signature in the sediment core}

410 Data obtained with the two analytical methodologies were in very good agreement $\left(R^{2}=0.99\right.$, slope of 411 linear regression $=0.99$ ) (Figure S2). The measured ${ }^{236} \mathrm{U} /{ }^{238} \mathrm{U}$ isotope ratios ranged between $412(7.33 \pm 2.20) \times 10^{-9}$ and $(2.70 \pm 0.37) \times 10^{-8}$ (see Figure 3$)$. These ratios were similar to the global fallout 413 values $\left(10^{-10}-10^{-7}\right)$ (Sakaguchi et al., 2009; Schneider et al., 2017), relative to the FDNPP range $414\left((3.42 \pm 0.52) \times 10^{-3}\right)\left(\right.$ Nishihara et al., 2012). The increase in ${ }^{236} \mathrm{U} /{ }^{238} \mathrm{U}$ values observed in the upper 415 section of the core is difficult to interpret because it may either reflect a slight impact of FDNPP derived $416 U$ releases or a local heterogeneity of the $U$ concentration in the environment. Nevertheless, it may be 417 deduced from these measurements that the isotopic signature of $U$ in these samples remained well 418 within the range of global fallout so that the potential fallout from the FDNPP is not detectable in these 419 samples. A part of U released from the FDNPP may also have been slowly incorporated into the bottom 
420 sediment, which could explain the slight increase of the ${ }^{236} \mathrm{U} /{ }^{238} \mathrm{U}$ isotope ratio observed in the upper

421 part of the core and the absence of a peak similar to that recorded for radiocesium and Pu. Moreover,

422 the geochemical behaviour of $\mathrm{U}$ may be different from that of radiocesium as it is likely contained in $\mathrm{UO}_{2}$

423 microparticles from the nuclear fuel in association with Pu impurities. The absence of the detection of

424 FDNPP -derived $U$ suggested that the concentrations in actinide released from the power plant were

425 lower than those already prevailing in the environment before the accident.

426

427

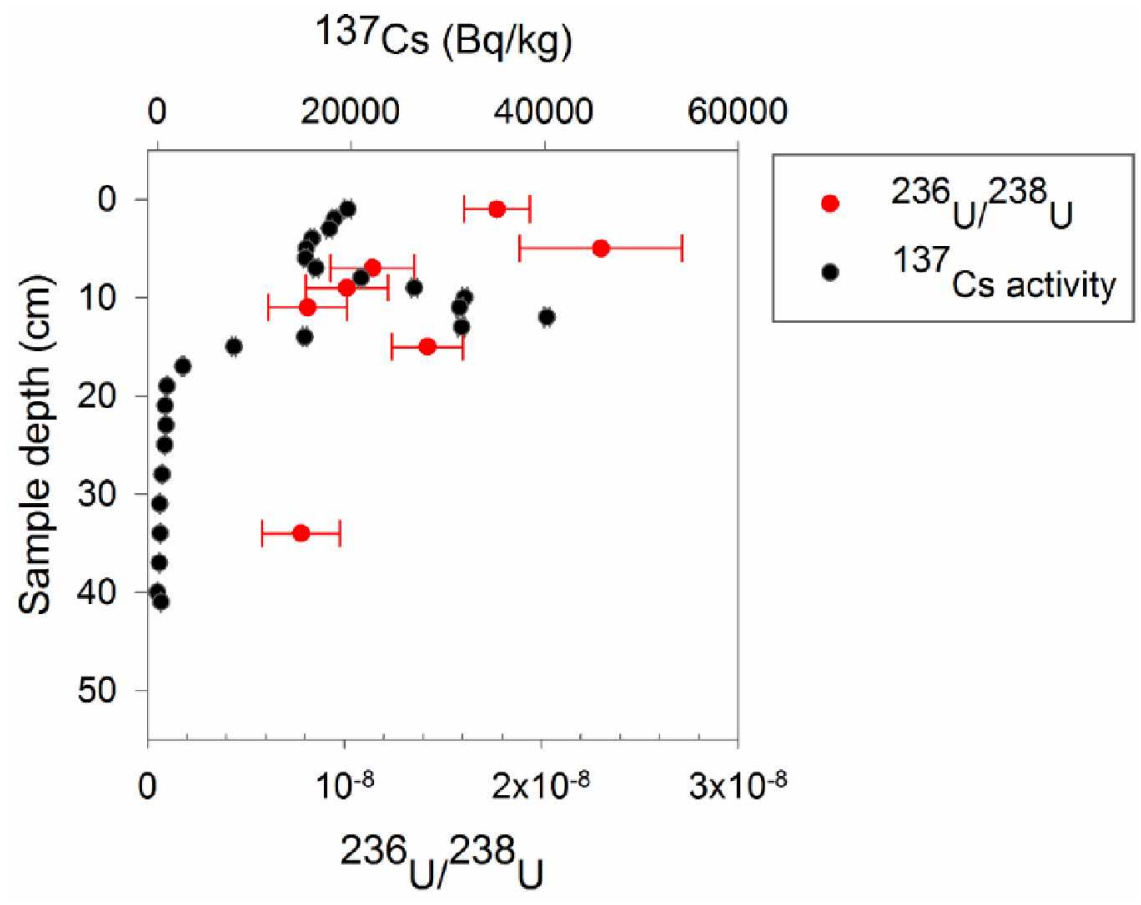

429 Figure 3: Evolution of the mean ${ }^{236} \mathrm{U} /{ }^{238} \mathrm{U}$ atom ratios (red dots) and ${ }^{137} \mathrm{Cs}$ activities (black dots) with depth in the 430 Mano Dam sediment core. Uncertainties are extended with a coverage factor of 2 . The uranium global fallout 431 signature $\left(10^{-10}-10^{-7}\right)$ falls beyond the range of the $X$-axis. 
436 Although it was not possible to calculate the $U$ source contributions as it was done for $\mathrm{Pu}$, theoretical

437 FDNPP-derived ${ }^{236} \mathrm{U}$ concentrations $\left({ }^{236} \mathrm{U}_{\mathrm{FDNPP}}\right)$ in the samples analysed in the current study were 438 estimated, based on the ${ }^{236} \mathrm{U} / \mathrm{Pu}=(0.46 \pm 0.12)$ ratio determined from the literature data(Nishihara et al. 439 2012). The maximum FDNPP-derived Pu concentration in soil samples analysed here reached $30.7 \pm 9.4$ $440 \mathrm{fg} / \mathrm{g}$ (Table S5). Accordingly, the theoretical ${ }^{236} \mathrm{U}$ concentration from the FDNPP was estimated to a 441 maximum of $14.1 \pm 5.6 \mathrm{fg} / \mathrm{g}$. Assuming a natural $U$ concentration in Japanese soils of $1.9 \pm 1.2$ $442 \mu \mathrm{g} / \mathrm{g}$ (Yoshida et al., 1998; Yoshida et al., 2000), the estimation of the theoretical $\left.{ }^{236} \mathrm{U}_{\mathrm{FDNPP}}\right|^{238} \mathrm{U}$ (i.e. the 443 potential impact of the FDNPP releases on the ${ }^{236} \mathrm{U} /{ }^{238} \mathrm{U}$ measured in the samples) was $(7.6 \pm 5.2) \times 10^{-9}$.

444 This theoretical calculation demonstrates that the occurrence of FDNPP-originating fallout is not 445 detectable in the analysed samples, because there is no significant difference between the ${ }^{236} \mathrm{U}_{\text {FDNPP }} /{ }^{238} \mathrm{U}$ 446 ratio in these sediment samples and the ${ }^{236} \mathrm{U} /{ }^{238} \mathrm{U}$ isotope ratio associated with the very heterogeneous 447 global fallout signal $\left(10^{-10}-10^{-7}\right)$

448 Similar calculations were performed to estimate the theoretical ${ }^{236} \mathrm{U}$ concentrations in the sediment 449 core, based on the FDNPP-derived Pu measurements in these samples. The resulting concentration 450 amounts to $1.7 \mathrm{fg} / \mathrm{g}$, which demonstrates that the FDNPP-originating $U$ fallout did not reach the region 451 of interest located at $\sim 40 \mathrm{~km}$ from the power plant. Nevertheless, the potential occurrence of $U$ 452 emissions by the FDNPP accident needs further investigations. In particular, similar analyses should be 453 performed in more contaminated areas such as in sediment accumulated in lakes located closer to the 454 FDNPP, where uranium may have been released in larger quantities. 


\section{Acknowledgements:}

458

459 The collection and the analysis of the sediment samples were funded by the TOFU (ANR-11-JAPN-001)

460 and the AMORAD (ANR-11-RSNR-0002) projects, funded by the French National Research Agency (ANR,

461 Agence Nationale de la Recherche). Hugo Jaegler received a PhD fellowship from the French Atomic

462 Energy Commission (CEA, Commissariat à l'Energie Atomique et aux Energies Alternatives). The authors

463 are grateful to the Fukushima Agricultural Technology Centre for providing the soil samples collected

464 before the FDNPP accident. The authors declare no competing financial interest 
Bu, W., Zheng, J., Ketterer, M.E., Hu, S., Uchida, S., Wang, X. (2017) Development and application of mass spectrometric techniques for the ultra-trace determination of ${ }^{236} U$ in environmental samples-A review. Analytica Chimica Acta. Buesseler, K., Dai, M., Aoyama, M., Benitez-Nelson, C., Charmasson, S., Higley, K., Maderich, V., Masque, P., Oughton, D., Smith, J.N. (2016) Fukushima Daiichi-Derived Radionuclides in the Ocean: Transport, Fate, and Impacts. Annual Review of Marine Science.

Cao, L., Ishii, N., Zheng, J., Kagami, M., Pan, S., Tagami, K., Uchida, S. (2017) Vertical distributions of Pu and radiocesium isotopes in sediments from Lake Inba after the Fukushima Daiichi Nuclear Power Plant accident: Source identification and accumulation. Applied Geochemistry 78, 287-294. determination of radiocesium $((135) \mathrm{Cs},(137) \mathrm{Cs})$ and plutonium $((239) \mathrm{Pu},(240) \mathrm{Pu})$ isotopes in river suspended particles by ICP-MS/MS and SF-ICP-MS. Talanta 159, 55-63.

Chartin, C., Evrard, O., Laceby, J.P., Onda, Y., Ottlé, C., Lefèvre, I., Cerdan, O. (2017) The impact of typhoons on sediment connectivity: lessons learnt from contaminated coastal catchments of the Fukushima Prefecture (Japan). Earth Surface Processes and Landforms 42, 306-317.

Chartin, C., Evrard, O., Onda, Y., Patin, J., Lefèvre, I., Ottlé, C., Ayrault, S., Lepage, H., Bonté, P. (2013) Tracking the early dispersion of contaminated sediment along rivers draining the Fukushima radioactive pollution plume. Anthropocene 1, 23-34.

Evrard, O., Laceby, J.P., Lepage, H., Onda, Y., Cerdan, O., Ayrault, S. (2015) Radiocesium transfer from hillslopes to the Pacific Ocean after the Fukushima Nuclear Power Plant accident: A review. Journal of Environmental Radioactivity 148, 92-110.

Evrard, O., Laceby, J.P., Onda, Y., Wakiyama, Y., Jaegler, H., Lefèvre, I. (2016) Quantifying the dilution of the radiocesium contamination in Fukushima coastal river sediment (2011-2015). Scientific Reports 6, 34828.

Evrard, O., Pointurier, F., Onda, Y., Chartin, C., Hubert, A., Lepage, H., Pottin, A.C., Lefevre, I., Bonte, P., Laceby, J.P., Ayrault, S. (2014) Novel insights into Fukushima nuclear accident from isotopic evidence of plutonium spread along coastal rivers. Environmental Science \& Technology 48, 9334-9340.

Fukushima, T., Arai, H. (2014) Radiocesium contamination of lake sediments and fish following the Fukushima nuclear accident and their partition coefficient. Inland Waters 4, 2014 - 2214.

Hirose, K., Igarashi, Y., Aoyama, M., Miyao, T., (2001) Long-term trends of plutonium fallout observed in Japan, in: Kudo, A. (Ed.), Radioactivity in the Environment. Elsevier, pp. 251-266.

Huon, S., Hayashi, S., Laceby, J.P., Tsuji, H., Onda, Y., Evrard, O. (2018) Source dynamics of radiocesiumcontaminated particulate matter deposited in an agricultural water reservoir after the Fukushima nuclear accident. Science of The Total Environment 612, 1079-1090.

Jaegler, H., Pointurier, F., Onda, Y., Hubert, A., Laceby, J.P., Cirella, M., Evrard, O. (2018) Plutonium isotopic signatures in soils and their variation (2011-2014) in sediment transiting a coastal river in the Fukushima Prefecture, Japan. Environmental Pollution 240, 167-176.

Kelley, J.M., Bond, L.A., Beasley, T.M. (1999) Global distribution of Pu isotopes and ${ }^{237} \mathrm{~Np}$. Science of The Total Environment 237-238, 483-500.

Kirchner, G., Bossew, P., De Cort, M. (2012) Radioactivity from Fukushima Dai-ichi in air over Europe; part 2: what can it tell us about the accident? Journal of Environmental Radioactivity 114, 35-40.

Kitamura, A., Kurikami, H., Sakuma, K., Malins, A., Okumura, M., Machida, M., Mori, K., Tada, K., Tawara, Y., Kobayashi, T., Yoshida, T., Tosaka, H. (2016) Redistribution and export of contaminated sediment 
within eastern Fukushima Prefecture due to typhoon flooding. Earth Surface Processes and Landforms 41, 1708-1726.

Kitamura, A., Yamaguchi, M., Kurikami, H., Yui, M., Onishi, Y. (2014) Predicting sediment and cesium-137 discharge from catchments in eastern Fukushima. Anthropocene 5, 22-31.

Laceby, J.P., Evrard, O., Smith, H.G., Blake, W.H., Olley, J.M., Minella, J.P.G., Owens, P.N. (2017) The challenges and opportunities of addressing particle size effects in sediment source fingerprinting: $A$ review. Earth-Science Reviews 169, 85-103.

Laceby, J.P., Huon, S., Onda, Y., Vaury, V., Evrard, O. (2016) Do forests represent a long-term source of contaminated particulate matter in the Fukushima Prefecture? Journal of Environmental Management $183,742-753$.

Lee, S.H., La Rosa, J., Gastaud, J., Povinec, P.P. (2005) The development of sequential separation methods for the analysis of actinides in sediments and biological materials using anion-exchange resins and extraction chromatography. Journal of Radioanalytical and Nuclear Chemistry 263, 419-425.

Lepage, H., Laceby, J.P., Bonté, P., Joron, J.-L., Onda, Y., Lefèvre, I., Ayrault, S., Evrard, O. (2016) Investigating the source of radiocesium contaminated sediment in two Fukushima coastal catchments with sediment tracing techniques. Anthropocene.

Matsuda, K., Takagi, K., Tomiya, A., Enomoto, M., Tsuboi, J.-i., Kaeriyama, H., Ambe, D., Fujimoto, K., Ono, T., Uchida, K., Morita, T., Yamamoto, S. (2015) Comparison of radioactive cesium contamination of lake water, bottom sediment, plankton, and freshwater fish among lakes of Fukushima Prefecture, Japan after the Fukushima fallout. Fisheries Science 81, 737-747.

Momoshima, N., Kakiuchi, H., Maeda, Y., Hirai, E., Ono, T. (1997) Identification of the contamination source of plutonium in environmental samples with isotopic ratios determined by inductively coupled plasma mass spectrometry and alpha-spectrometry. Journal of Radioanalytical and Nuclear Chemistry 221, 213-217.

Muramatsu, Y., Yoshida, S., Tanaka, A. (2003) Determination of Pu concentration and its isotope ratio in Japanese soils by HR-ICP-MS. Journal of Radioanalytical and Nuclear Chemistry 255, 477-480.

Nishihara, K., Iwamoto, H., Suyama, K. (2012) Estimation of fuel compositions in Fukushima-Daiichi nuclear power plant. JAEA-Data/Code 2012, http://jolissrch-inter.tokai-sc.jaea.go.jp/pdfdata/JAEA-DataCode-2012-018.pdf (2012)(Date of access: 29/02/2016).

Ohtsuka, Y., T., I., Kakiuchi, H., Y., T., Hisamatsu, S., J., I. (2004) Evalutation of 239+240Pu, 137Cs and natural $210 \mathrm{~Pb}$ fallout in agricultural upland fields in Rokkasho, Japan. Journal of Radioanalytical and Nuclear Chemistry 261, 625-630.

Sakaguchi, A., Kawai, H., Steier, P., Imanaka, T., Hoshi, M., Endo, I., Zhumadilov, K., M., Y. (2010) Feasibility of using $236 \mathrm{U}$ to reconstruct close-in fallout deposition from the hiroshima atomic bomb. Science of The Total Environment 408, 5392 - 5398.

Sakaguchi, A., Kawai, K., Steier, P., Quinto, F., Mino, K., Tomita, J., Hoshi, M., Whitehead, N., Yamamoto, M. (2009) First results on ${ }^{236} \mathrm{U}$ levels in global fallout. Science of The Total Environment 407, 4238-4242.

Sakaguchi, A., Steier, P., Takahashi, Y., Yamamoto, M. (2014) Isotopic Compositions of ${ }^{236} \mathrm{U}$ and Pu Isotopes in "Black Substances" Collected from Roadsides in Fukushima Prefecture: Fallout from the Fukushima Dai-ichi Nuclear Power Plant Accident. Environmental Science \& Technology 48, 3691-3697.

Salbu, B. (2011) Radionuclides released to the environment following nuclear events. Integrated Environmental Assessment and Management 7, 362-364.

Schneider, S., Bister, S., Christl, M., Hori, M., Shozugawa, K., Synal, H.-A., Steinhauser, G., Walther, C. (2017) Radionuclide pollution inside the Fukushima Daiichi exclusion zone, part 2: Forensic search for the "Forgotten" contaminants Uranium-236 and plutonium. Applied Geochemistry.

Schneider, S., Walther, C., Bister, S., Schauer, V., Christl, M., Synal, H.-A., Shozugawa, K., Steinhauser, G. (2013) Plutonium release from Fukushima Daiichi fosters the need for more detailed investigations. Scientific Reports 3. 
Schwantes, J.M., Orton, C.R., Clark, R.A. (2012) Analysis of a Nuclear Accident: Fission and Activation Product Releases from the Fukushima Daiichi Nuclear Facility as Remote Indicators of Source Identification, Extent of Release, and State of Damaged Spent Nuclear Fuel. Environmental Science \& Technology 46, 8621-8627. Shinonaga, T., Steier, P., Lagos, M., Ohkura, T. (2014) Airborne Plutonium and Non-Natural Uranium from the Fukushima DNPP Found at $120 \mathrm{~km}$ Distance a Few Days after Reactor Hydrogen Explosions. Environmental Science \& Technology 48, 3808-3814.

Tanaka, K., Iwatani, H., Sakaguchi, A., Fan, Q., Takahashi, Y. (2015) Size-dependent distribution of radiocesium in riverbed sediments and its relevance to the migration of radiocesium in river systems after the Fukushima Daiichi Nuclear Power Plant accident. Journal of Environmental Radioactivity 139, 390-397.

571 Tanimizu, M., Sugiyama, N., Ponzevera, E., Bayon, G. (2013) Determination of ultra low ${ }^{236} U /{ }^{238} \mathrm{U}$ isotope

ratios by tandem quadrupole ICP-MS. Journal of Analytical Atomic Spectrometry 28, 1372-1376.

Trémillon, B. (1965) Les séparations par les résines échangeuses d'ions. Gauthier-Villars.

Xu, C., Zhang, S., Sugiyama, Y., Ohte, N., Ho, Y.F., Fujitake, N., Kaplan, D.I., Yeager, C.M., Schwehr, K., Santschi, P.H. (2016) Role of natural organic matter on iodine and Pu distribution and mobility in environmental samples from the northwestern Fukushima Prefecture, Japan. Journal of Environmental Radioactivity 153, 156-166.

Yamada, S., Kitamura, A., Kurikami, H., Yamaguchi, M., Malins, A., Machida, M. (2015) Sediment and ${ }^{137}$ Cs transport and accumulation in the Ogaki Dam of eastern Fukushima. Environmental Research Letters 10, 014013.

Yamamoto, M., Sakaguchi, A., Ochiai, S., Takada, T., Hamataka, K., Murakami, T., Nagao, S. (2014) Isotopic $\mathrm{Pu}, \mathrm{Am}$ and $\mathrm{Cm}$ signatures in environmental samples contaminated by the Fukushima Dai-ichi Nuclear Power Plant accident. Journal of Environmental Radioactivity 132, 31-46.

Yamamoto, M., Takada, T., Nagao, S., Koike, T., Shimada, K., Hoshi, M., Zhumadilov, K., Shima, T., Fukuoka, M., Imanaka, T., Endo, S., Sakaguchi, A., Kimura, S. (2012) An early survey of the radioactive contamination of soil due to the Fukushima Dai-ichi Nuclear Power Plant accident, with emphasis on plutonium analysis. Geochemical Journal 46, 341-353.

Yamashiki, Y., Onda, Y., Smith, H.G., Blake, W.H., Wakahara, T., Igarashi, Y., Matsuura, Y., Yoshimura, K. (2014) Initial flux of sediment-associated radiocesium to the ocean from the largest river impacted by Fukushima Daiichi Nuclear Power Plant. Scientific Reports 4, 3714.

Yang, G., Tazoe, H., Yamada, M. (2016) Determination of ${ }^{236} \mathrm{U}$ in environmental samples by single extraction chromatography coupled to triple-quadrupole inductively coupled plasma-mass spectrometry. Analytica Chimica Acta.

Yoshida, S., Muramatsu, Y., Tagami, K., Uchida, S. (1998) Concentrations of lanthanide elements, Th, and $\mathrm{U}$ in 77 Japanese surface soils. Environment International 24, 275-286.

Yoshida, S., Muramatsu, Y., Tagami, K., Uchida, S., Ban-nai, T., Yonehara, H., Sahoo, S. (2000) Concentrations of uranium and ${ }^{235} \mathrm{U} /{ }^{238} \mathrm{U}$ ratios in soil and plant samples collected around the uranium conversion building in the JCO campus. Journal of Environmental Radioactivity 50, 121 - 172.

Zhang, Y., Zheng, J., Yamada, M., Wu, F., Igarashi, Y., Hirose, K. (2010) Characterization of Pu concentration and its isotopic composition in a reference fallout material. Science of The Total Environment 408, 1139-1144.

Zheng, J., Tagami, K., Bu, W., Uchida, S., Watanabe, Y., Kubota, Y., Fuma, S., Ihara, S. (2014) ${ }^{135} \mathrm{Cs} /{ }^{137} \mathrm{Cs}$ isotopic ratio as a new tracer of radiocesium released from the Fukushima nuclear accident. Environmental Science \& Technology 48, 5433-5438.

Zheng, J., Tagami, K., Watanabe, Y., Uchida, S., Aono, T., Ishii, N., Yoshida, S., Kubota, Y., Fuma, S., Ihara, S. (2012b) Isotopic evidence of plutonium release into the environment from the Fukushima DNPP accident. Scientific Reports 2, 304. 
608 